\title{
Modelo para armar: concepciones sobre desarrollo y autogestión en el sindicalismo latinoamericano de orientación socialcristiana en los años setenta
}

\section{Model to Assemble: Conceptions on Development and Self-management in Latin American Unionism with a Christian Social Orientation in the 1970s}

\author{
Gabriela Scodeller* \\ (D) https://orcid.org/0000-0001-7919-4060 \\ Instituto de Ciencias Humanas, Sociales y Ambientales \\ Centro Científico Tecnológico Mendoza-Conicet \\ Facultad de Ciencias Políticas y Sociales \\ Universidad Nacional de Cuyo, Argentina \\ g_scodeller@yahoo.com.ar
}

Resumen: El artículo se propone revisar la concepción sobre desarrollo y organización económica presente en el sindicalismo latinoamericano de orientación socialcristiana en las décadas en que, tensionados por la revolución cubana y la Alianza para el Progreso, los distintos actores sociales de la región

* Doctora en Historia, Universidad Nacional de la Plata. Línea de investigación: procesos y experiencias de formación sindical en Argentina y América Latina.

cómo cITAR: Scodeller, G. (2021). Modelo para armar: concepciones sobre desarrollo y autogestión en el sindicalismo latinoamericano de orientación socialcristiana en los años setenta. Secuencia (110), e1745. DoI: https://doi.org/10.18234/secuencia.v0i110.1745

c) 9

Esta obra está protegida bajo una Licencia Creative Commons Atribución-NoComercial 4.0 Internacional. 
no estuvieron al margen de los debates sobre el desarrollo. Nos interesa analizar la propuesta de autogestión que formula la Central Latinoamericana de Trabajadores (CLAT) como respuesta, donde conjuga en clave latinoamericana elementos de su tradición doctrinaria con la experiencia yugoslava, apelando además a otras experiencias europeas y de la región.

Palabras clave: América Latina; años setenta; sindicalismo cristiano; autogestión; formación sindical.

Abstract: The article seeks to review the conception of development and economic organization present in Latin American trade unionism with a Christian Social orientation in the decades in which, torn between the Cuban Revolution and the Alliance for Progress, the various social actors of the region were not exempt from debates on development. We are interested in analyzing the self-management proposal put forward by the Central Latinoamericana de Trabajadores (CLAT) as a response, which combines features of their doctrinal tradition with the Yugoslavian tradition, while appealing to other experiences from both Europe and the region.

Keywords: Latin America; 1970s; christian unionism; self-management; union training.

Recibido: 14 de mayo de 2019 Aceptado: 21 de abril de 2020

Publicado: 26 de abril de 2021

\section{INTRODUCCIÓN}

Tas décadas de crecimiento económico que siguieron a la segunda guerra Lmundial no resolvieron el problema del bienestar. El asunto del desarro-
llo -y conjuntamente el de la planificación- se convirtieron, a pesar de los matices en términos de diagnóstico o diseño de estrategias y programas, en una cuestión ineludible en las agendas políticas y en el debate académico e intelectual entre, o al interior mismo, de los bloques en que la guerra fría organizaba el (des)orden emanado de la contienda mundial. En este concierto 
bipolar, una tercera voz bregaba por hacerse oír, sobre todo desde el tercer mundo: el movimiento de los "no alineados". 1 Tensionada más directamente por la revolución cubana (1959) y la Alianza para el Progreso (1961) como modelos antagónicos de proyección del desarrollo en la región, América Latina no estuvo al margen de dichas discusiones.

Se adosaba otro ingrediente a la polémica sobre el (sub)desarrollo: la cuestión de la participación. A la creciente conflictividad política y social de los años sesenta y setenta se sumaban, en los países noratlánticos, los nuevos problemas que planteaba el acelerado proceso de tecnificación; tornando necesaria la búsqueda de formas alternativas de articular las relaciones obrero-patronales al interior de las fábricas, y de contener la conflictividad por fuera de estas. Frente a la efervescencia laboral se puso en discusión la ampliación de los canales de participación en la toma de decisiones, y es aquí donde el modelo yugoslavo de autogestión se volvió un faro a observar.

Puesto que representaba una vía alternativa entre los modelos socialista y capitalista, remitiendo directamente a las problemáticas de la planificación y de la participación, este modelo autogestionario resultó atractivo para un conjunto heterogéneo de actores. Así, las agendas de occidente se cruzaron con el interés de los propios líderes yugoslavos por difundir su modelo, dando lugar a la circulación del mismo por un sinnúmero de espacios y redes académico-intelectuales, de organismos estatales e intergubernamentales (Zaccaria, 2018). La Organización Internacional del Trabajo (огт) cumplió un papel central en esta dinámica, a partir del análisis de los distintos modelos de planificación, participación y gestión que realizaba su Instituto Internacional de Estudios Laborales (Maul, 2017), y más puntualmente a través del estudio y divulgación de la experiencia yugoslava. ${ }^{2}$ Los usos de estos insumos variaron según el horizonte de lectura. Pero en general la experiencia fue acotada al nivel de la empresa, estando el interés puesto principalmente en el funcionamiento de este sistema como forma de gestionar la fuerza de trabajo. En un sentido más amplio, suponía la introducción de un concepto menos radical de participación -donde el poder de decisión era compartido con la gerencia

${ }^{1}$ Recordemos que el mismo tomó forma al amparo del gobierno yugoslavo, país que celebró la I Conferencia del Movimiento de Países No Alineados, en 1961.

${ }^{2}$ Ya en 1962 publicó un extenso volumen titulado La gestión obrera de las empresas en Yugoslavia. 
y/o con el Estado- bajo la idea de que ello se convertía en factor para resolver o anular los conflictos sociales (Zaccaria, 2018, p. 225).

A la par, la experiencia yugoslava despertó un amplio interés entre agrupamientos sociales, sindicales y políticos muy diversos en términos de adscripciones ideológicas; también aquí generando una diversidad de apropiaciones. En este artículo nos interesa desandar la apropiación de dicho concepto de autogestión en la construcción que articuló el sindicalismo de raíz cristiana en América Latina. Desde que surgió en Santiago de Chile en 1954, la Confederación Latinoamericana de Sindicalistas Cristianos (CLASC) agrupó a nivel regional a los trabajadores de dicho credo. Con los años amplió su horizonte de representación religiosa, buscando además nuclear no sólo a trabajadores sindicalizados sino a organizaciones de pobladores, cooperativistas, campesinos, mujeres y jóvenes. Así, en 1971 pasó a llamarse Central Latinoamericana de Trabajadores (CLAT). ${ }^{3}$ Transitó un camino propio y original, con autonomía de las instituciones con las cuales se la ha solido identificar, sea la Iglesia católica, los partidos demócrata cristianos, ${ }^{4}$ o la propia federación mundial de la que formaba parte, la Confederación Mundial de Trabajadores (смт). ${ }^{5}$ Su historia se ubicó más bien próxima al proceso de radicalización por el que atravesaron distintos sectores religiosos del continente en el marco de renovación abierto por el Concilio Vaticano II (1962-1965) y posteriormente por la II CELAM (1968), cuyo correlato fue una acelerada

${ }^{3}$ Desde 1967 su sede se trasladó a Caracas. Su mayor influencia estuvo entre los sectores campesinos y urbanos pobres de los países menos desarrollados, logrando instalarse con mayor fuerza en Venezuela, Ecuador, República Dominicana, Colombia y otros países de la zona del Caribe. Se estima que para 1968 aglutinaba entre 500 y 1000000 de adherentes y simpatizantes. Según la propia organización, la cifra llegaría a los 5000000 (Máspero, 1964, pp. 161-181). Obtuvo fondos para la realización de sus actividades del Instituto de Solidaridad Internacional (IsI) de la Fundación Konrad Adenauer -su principal aportante-y de la Fundación Misereor (ambas alemanas), de la Fundación Alberto Hurtado de Chile y del Fondo de Solidaridad de la CISC/СMT, entre otros aportes menores provenientes de sindicatos cristianos europeos (belgas y franceses, entre otros). Para una historia descriptiva institucional y distintas caracterizaciones se pueden consultar los estudios de Alexander (2009, pp. 199-227); Córdova (1968); Francis (1968); Scodeller (2020); Wahlers (1991).

${ }^{4}$ Por ejemplo, si bien en la región los gobiernos de Eduardo Frei Montalva, en Chile y de Rafael Caldera, en Venezuela fomentaron y financiaron algunas actividades del sindicalismo cristiano en sus países, ello no implicó un alineamiento de la CLAsc/CLAT con los gobiernos democratacristianos.

${ }^{5}$ Más bien la CLASC/CLAT influyó sobre esta, al ser la principal organización regional. Para 1968 representaba 40\% de sus afiliados. Sobre la CMT -previamente denominada Confederación Internacional de Sindicatos Cristianos (CISC)- véase Pasture (1994). 
dinámica de secularización. ${ }^{6}$ En la coyuntura del año 1968, la CLAsc puede ubicarse próxima a la corriente revolucionaria (aunque sin adscribir a la lucha armada y con puntos de diálogo con la línea reformista y desarrollista -continuadora del Concilio Vaticano II-). ${ }^{7}$ Llegó a ser la segunda organización sindical en la región después de la Organización Regional Interamericana de Trabajadores (ORIT) $)^{8}$ con quien se disputaba la influencia sobre las masas obreras no comunistas del continente.

Nos proponemos, entonces, revisar cómo la CLASC/CLAT se ubicó en la mencionada discusión sobre el desarrollo; analizar cómo fue entramando un diagnóstico sobre el subdesarrollo regional y buscando una alternativa propia, que la diferenciase de los bloques antagónicos de la guerra fría. Entrelazando concepciones provenientes de su raigambre socialcristiana con la experiencia de autogestión yugoslava, sostenemos que aparecerá formulada la autogestión como alternativa de desarrollo. Asumidas la primera en clave revolucionaria y la segunda en clave latinoamericana, buscamos ver cómo se fusionaron en una propuesta propia que implicó una forma de organización económica, pero también política y social. Así, lo que nos interesa conocer es el proceso por el cual una organización sindical cristiana llegó a elaborar la siguiente afirmación:

El socialismo de los trabajadores debe ser la primacía del trabajo y de los trabajadores sobre el capital, la técnica y el poder... Políticamente este socialismo es el poder del pueblo organizado. Económicamente, es la propiedad social de los medios de producción, la planificación democrática y la autogestión de la

${ }^{6}$ En este marco muchos grupos cristianos tomarían un rumbo aún más radical, comprometiéndose en los conflictos y luchas de los oprimidos -lo que en muchos casos se realizó por la vía armada-. Por su parte, la Teología de la Liberación acompañó este proceso proponiendo una lectura marxista de la Biblia con base en la cual analizar la realidad socioeconómica de la región.

${ }^{7}$ Para una caracterización de estas líneas véase Silva Gotay (1981, cap. 1). La propia organización identificaba tres corrientes dentro de las iglesias latinoamericanas: una tradicionalista, la capitalista y otra revolucionaria. Central Latinoamericana de Trabajadores (s. f. a, tema XII, p. 23).

8 Afiliada a la Confederación Internacional de Organizaciones Sindicales Libres (cIOsL). Sobre la ORIT consultar a Alexander (2009, pp. 109-172). Para un estudio comparativo con su par europea, véase Rodríguez García (2010). Sobre la cioss véase Carew, Dreyfus, Van Goethem, Gumbrell-McCormick y Van der Linden (2000). Para un análisis de las relaciones de la ORIT con la AFL-CIO, véase Walters Jr. y Van Goethem (2013). 
economía; socialmente, es la autogestión proyectada a la sociedad global como medio de crear el cuadro de libertad y responsabilidad más amplios posibles. ${ }^{9}$

Atendiendo al contexto internacional previamente descrito, nos preguntamos qué tomó la CLASC/CLAT del modelo yugoslavo y cómo llegó a él. No pretendemos observar sólo las distintas concepciones en debate sino también los modos, materiales y lugares del intercambio, a los actores intervinientes como las traducciones situadas y sus resignificaciones. ${ }^{10}$ Para observar esta dinámica nos servimos de una diversidad de fuentes provenientes de la propia organización sindical. ${ }^{11}$

Ubicamos la mirada entre 1968 y 1978, entendiendo que este es el periodo de mayor productividad y radicalidad en los planteos que la Central iría elaborando en torno a la autogestión como modelo propio. Las fechas corresponden al momento en que, como veremos, una serie de eventos marcan el inicio de un interés sistemático por parte de la CLASC en la experiencia yugoslava, hasta las definiciones más acabadas a que llegará en el marco del VII Congreso de la CLAT (1978).

Consideramos que esta interpelación sobre un objeto clásico de la historiografía laboral como son las organizaciones obreras -aunque en este caso se trate de una muy poco explorada-, contribuye a ampliar el campo de la

9 La cita corresponde al documento "Estrategia y política" discutido en el VI Congreso de 1971, citado en Wahlers (1991, pp. 259-260).

${ }_{10}$ M. Espagne (1999) nos permite pensar las transferencias culturales como una traducción hacia otros códigos, siendo el contexto de recepción determinante en la selección y reformulación de aquello que se desplaza. Sin embargo, tomamos la advertencia que formulan M. Werner y B. Zimmermann (2006) en cuanto a que, remitirnos sólo a los estudios de transferencia nos ubicaría frente a una mirada limitada donde las transacciones se ciñen a dos polos, presuponiendo una direccionalidad; existiendo además cierta invariabilidad en las categorías de análisis y marcos de referencia iniciales. Estos autores sugieren un enfoque más relacional, que atienda a la complejidad y ubique su foco en la cuestión del cambio, donde la importancia de la intersección no se limite al momento de encuentro sino al proceso, existiendo una multiplicidad de posibles entrecruzamientos, donde las transformaciones pueden ser simétricas o asimétricas, y multidireccionales.

${ }^{11}$ Hemos consultado las distintas prensas de la organización, libros, documentos y folletos publicados por su sello editorial Fondo Latinoamericano de Cultura Popular (FLACPO), como así también cuadernillos e informes referidos a sus actividades e instituciones educativas. Las fuentes editadas citadas en este artículo se encuentran disponibles en el archivo del Instituto Internacional de Historia Social (IIHS), Amsterdam, mientras los documentos internos han sido consultados en el Centro de Documentación e Investigación sobre Religión, Cultura y Sociedad (KADOC), de Lovaina. 
historia social de las y los trabajadores, combinando elementos característicos de "la vieja, la nueva y la historia global del trabajo" (Van der Linden, 2009). Nos interesa explorar una serie de cruces poco atendidos en la historiografía del trabajo latinoamericana. Por un lado, no se ha reparado en el vínculo entre sindicalismo y religión, como sí sucede en el ámbito europeo, aunque a su vez este raramente ponga sus investigaciones en diálogo con las experiencias latinoamericanas (Horn, 2008, 2015; Horn y Gerard, 2001; Van Voss, Pasture y Maeyere, 2005). Por otro, tampoco se ha detenido a mirar al sindicalismo como actor relevante en el debate sobre desarrollo y participación iniciado en la segunda posguerra, salvo contadas excepciones (Maul, 2017; Rodríguez García, 2010).

En línea con estudios recientes que interpretan la guerra fría como un fenómeno global (Brands, 2010; Saull, 2004) otorgando agencia a los actores del sur y distanciándose por tanto de aquellas interpretaciones en que la iniciativa proviene unidireccionalmente del norte; nos interesa discutir una imagen rígida y estática del universo sindical de aquellos años. Cuando se le da protagonismo, este aparece lleno de yuxtaposiciones y entramados complejos. Esta entrada al mundo del trabajo nos permite reponer a una organización que ha quedado algo soslayada en el mapa de la contienda bipolar, posiblemente por la dificultad de ubicar a la CLASC/CLAT en el mismo, dadas las ambivalencias que la tensionaron.

En las páginas que siguen, en primer lugar y como marco de referencia de la discusión, mencionaremos un conjunto de encuentros en los que la CLASC/CLAT participó, dando cuenta de su mirada y posicionamientos sobre la cuestión del desarrollo en general, sus definiciones al respecto e influencias ideológico-doctrinarias en las que abrevó. Exploraremos cómo ello se conectaba con el tema de la participación de los trabajadores y, más puntualmente, cómo los llevó a pensar el tema de la autogestión. En el segundo apartado nos dedicaremos a analizar cuáles fueron sus exploraciones al respecto: los diálogos con la experiencia yugoslava de modo directo, pero también mediatizada por sus compañeros de la Confederación Francesa Democrática del Trabajo (СFDT); recorrido de elaboración teórica que fue revisado y reflexionado a la luz de una experiencia más cercana: el proceso atravesado en el Chile de la Unidad Popular.

Luego, en el tercer apartado, mencionaremos otras experiencias históricas y contemporáneas que, aunque en menor medida, fueron objeto de estudio por parte de la CLAT, en tanto que constituían insumos para imagi- 
nar la nueva sociedad que debían construir los trabajadores, y en la cual la autogestión era el eje articulador. Si bien como veremos en la concepción de la CLASC/CLAT la autogestión constituía un proceso integral, en el segundo apartado el eje de análisis será más bien económico y el núcleo de la discusión será la empresa; mientras que en el tercero el eje se vuelve más político y lo que se pone en debate es el Estado. Si en el anterior veremos el esfuerzo de la CLASC/CLAT por buscar experiencias que informasen su definición de autogestión, en el último encontraremos las tareas que llevó a cabo para difundirlas al interior de la propia organización. Finalmente, esbozaremos cuál fue el aporte creativo y los límites del recorrido realizado por esta organización latinoamericana.

\section{QUÉ DESARROLLO PARA QUIÉN}

Abogando por una posición anticapitalista, antimperialista (incluyendo por igual a ambos bloques de la guerra fría $)^{12}$ y tercermundista, que a su vez apelaba y promovía la existencia de una identidad común latinoamericana, la CLASC/CLAT no dejó de involucrarse en la discusión sobre el desarrollo, interviniendo en algunos espacios organizados por distintos organismos internacionales.

Enviaron, por ejemplo, un delegado a la XII Reunión de la Comisión Económica para América Latina y el Caribe (CEPAL) de 1967, quien se manifestó en contra de "una integración capitalista realizada en el cuadro político del panamericanismo". Desarrollo e integración siempre aparecerían articulados en el planteo de la organización sindical. Allí sostuvieron que la integración debía ser política, social y cultural además de económica; de los pueblos y no de gobiernos o monopolios extranjeros. ${ }^{13}$ Lo interesante es que su clara denuncia al sistema no la ubicó al margen de estas instancias de debate, sino que, por el contrario, las entendieron como espacios de disputa, en los que

12 Para la Central la contradicción entre norte y sur en términos de desarrollo prevalecía sobre aquella que oponía a este y oeste en términos de ideologías: "capitalismo o comunismo" -decían- no era más que un "dilema imperialista". Central Latinoamericana de Trabajadores (1978, p. 65).

13 "Los trabajadores hacia la integración: queremos una vía no capitalista y latinoamericana. Ponencia de la CLASC en reunión de CEPAL", CLASC. Vocero del sindicalismo revolucionario en América Latina, Caracas, junio de 1967, p. 2. 
buscaron poner sus lineamientos sobre la mesa. Para ello se preocuparon por informarse y formarse, y lo hicieron dentro del universo católico.

Así, a fines de ese año 17 dirigentes de la ClAsc participaron de un seminario de seis semanas de duración, en Santiago de Chile, denominado Seminario Latinoamericano sobre Doctrina Global del Desarrollo. Fue el segundo de este tipo, organizado por el Instituto Latinoamericano de Doctrina y Estudios Sociales (ILADES). Su objetivo era "dotar a los dirigentes sindicales de los conocimientos necesarios para una efectiva participación de los trabajadores organizados en los procesos de desarrollo de nuestros países en la perspectiva del hombre, de todo el hombre y de todos los hombres", ${ }^{14}$ frase que aludía directamente a la impronta humanista del dominico Louis Joseph Lebret. La Teología del Desarrollo de la que este fue el principal exponente resultó muy influyente en distintos círculos vinculados al pensamiento cristiano en América Latina. Recordemos que su concepción sobre el "desarrollo integral del hombre” impregnó al Concilio Vaticano II (Silva Gotay, 1981, pp. 41, 52-53) y para el tema que nos convoca, sus obras estuvieron entre las más citadas por la CLASC/CLAT. ${ }^{15}$ Además, Lebret fue muy influyente en Brasil, sobre todo en obispos como Hélder Câmara, a quienes la clAsc leyó con asiduidad.

Pero la CLASC no sólo estaba interesada en poner en juego el contenido que se debatía detrás del desarrollo y la integración en instancias gubernamentales o supranacionales, sino que se aseguró de discutirla entre pares, en ámbitos obreros. En este sentido, en marzo de 1968 se realizó un importante encuentro en Santo Domingo, ${ }^{16}$ la Primera Conferencia Sindical sobre Desa-

14 "Dirigentes sindicales a seminario sobre doctrina global del desarrollo", cLASC. Vocero del sindicalismo revolucionario en América Latina, Caracas, octubre de 1967, p. 3, resaltado en original. Vale la pena señalar que en 1966 se realizó, también en Santiago de Chile, organizado conjuntamente por la OIT y la CEPAL, un Curso para Sindicalistas Latinoamericanos sobre Planificación y Desarrollo Económico y Social. De estas instancias de formación participaron en su gran mayoría cuadros de la ORIT. Esta última, ahora en colaboración con la Organización de Estados Americanos (oEA), ese mismo año organizó un Seminario Internacional sobre Integración Económica y Social de América Latina. Como se ve, el tema del desarrollo resultaba acuciante para el sindicalismo latinoamericano en sus distintas vertientes ideológicas (Scodeller, 2017).

${ }^{15}$ Por ejemplo: Desarrollo - Revolución solidaria y Manifiesto por una civilización solidaria (publicados en español en la década de los años sesenta). Sobre la influencia de otros pensadores del cristianismo social francés como P. Teilhard de Chardin, J. Maritain, E. Mounier, entre otros, véase Löwy (1999).

${ }^{16}$ La elección del lugar -"país símbolo de la lucha contra el colonialismo interno y el colonialismo internacional"- tenía un peso simbólico: homenajear a quienes empuñaron las armas contra la dictadura y para impedir la ocupación militar por Estados Unidos. Por ello, "significa 
rrollo e Integración de América Latina, que se presentó como un espacio en el que los trabajadores, convidados de piedra en la discusión sobre el desarrollo y la integración, finalmente podrían discutir y definir desde sus intereses, necesidades y aspiraciones, "una estrategia, una política y una táctica, y sobre todo una acción mancomunada [...] que oriente y estimule la marcha de los trabajadores en los procesos del desarrollo y de la integración de nuestros pueblos". La misma convocatoria llamaba a pensar, estudiar y debatir, a la vez que a realizar "una profunda revolución social, cultural, política y económica" como "único camino para un desarrollo e integración a la medida del hombre y de los pueblos latinoamericanos". ${ }^{17}$

Dicha Conferencia se definió a favor de una tercera vía de desarrollo: aquella que encarnaban los pueblos pobres para lograr la liberación, rechazando a los imperialismos (tanto capitalista como comunista). Era necesario, argumentaban, dejar de copiar e importar fórmulas de cada rincón del mundo ya que los caminos y modelos para el desarrollo y la liberación latinoamericana debían "nacer dentro de las clases populares y ser alumbradas por el calor de la lucha, de la acción, del pensamiento encarnado en el proceso revolucionario práctico de todos los días". ${ }^{18}$

Entre diversas denuncias, enfatizaban que los "procesos desarrollistas, implantados a nivel de gobiernos, empresarios, organismos internacionales y tecnocracias, son solamente una nueva presentación del capitalismo tradicional bajo las nuevas formas de neocapitalismo, que trata de reforzar en supercapitalismo el poder de las oligarquías nacionales, fortaleciendo inevitablemente a los monopolios extranjeros".

señalar claramente que el desarrollo y la integración que buscamos no es la misma que buscan los grupos imperialistas y las oligarquías nacionales. Significa expresar que el desarrollo y la integración que queremos es con el pueblo y contra los grupos extraños a la realidad de nuestros países." "Primera conferencia sindical para el desarrollo y la integración de América Latina", CLASC. Vocero del sindicalismo revolucionario en América Latina, Caracas, marzo de 1968, p. 2.

17 "Primera conferencia sindical para el desarrollo y la integración de América Latina. Punto de encuentro de aspiraciones y necesidades comunes", CLASC. Vocero del sindicalismo revolucionario en América Latina, Caracas, abril de 1968, p. 8.

${ }_{18}$ "Los pueblos dirán en cada caso la última palabra", CLASC. Vocero del sindicalismo revolucionario en América Latina, Caracas, junio-julio de 1968, p. 2. 
Y que "el actual proceso de integración latinoamericana representa en definitiva la última etapa de consolidación del imperialismo capitalista en América Latina" ${ }^{19}$

La Carta de Santo Domingo, emanada de aquel evento y firmada por dirigentes sindicales de 26 países latinos pertenecientes a la CLASC, agregaba que el "desarrollo integral" en América Latina, en la perspectiva de liberar a sus pueblos, suponía la creación de una "nueva sociedad" y la "formación de hombres nuevos"; así, sus resultados serían evaluados en función de la "promoción humana y popular" que lograse producir. En otras palabras, nada de lo anterior podría realizarse sin una real y completa (económica, social, política y cultural) integración latinoamericana y no panamericana. ${ }^{20}$ Como se puede observar, la CLASC/CLAT anclaba algunas de sus definiciones en los marcos de la Doctrina Social de la Iglesia y en la Teología del Desarrollo, aunque paulatinamente iría introduciendo elementos que hacían a su ubicación específica como actor sindical del tercer mundo y de una América Latina donde bullían ideas y prácticas revolucionarias, en donde el movimiento obrero constituía un actor "irremplazable" para terminar con una Latinoamérica "dominada y dependiente". ${ }^{21}$

En esa línea, para 1972 el diagnóstico de la CLAT -presentado en la III Conferencia de las Naciones Unidas sobre Comercio y Desarrollo realizada

19 "Carta de los trabajadores para la liberación y la unidad de los pueblos de América Latina", CLASC. Vocero del sindicalismo revolucionario en América Latina, Caracas, junio-julio de 1968, pp. 6-7.

${ }^{20}$ En sintonía, la CMT organizó la Primera Conferencia Sindical Mundial sobre los Problemas del Tercer Mundo (Roma, octubre de 1968), cuyo eje principal fue el tema del desarrollo. Entre otros puntos, allí se resolvió realizar un estudio profundo y sistemático del tema a fin de arribar a una definición original y a una estrategia sindical nueva. "Una estrategia global del desarrollo y un programa concreto de acción sindical. Primera conferencia sindical mundial sobre los problemas del tercer mundo", CLASC. Vocero del sindicalismo revolucionario en América Latina, Caracas, octubre de 1968, p. 2. A esta reunión siguieron encuentros en los distintos continentes que culminaron en 1973 en la Primera Conferencia de Trabajadores del Tercer Mundo, lo que muestra el persistente interés en discutir la cuestión del desarrollo por parte del sindicalismo nucleado en torno a esta confederación, expresándose en la misma tónica que venimos relatando. "Trabajadores de todo el mundo reunidos en Ginebra: el desarrollo como proceso permanente de liberación”, CLAT. Vocero del Movimiento de los Trabajadores comprometido con la liberación de los pueblos de América Latina, Caracas, octubre-noviembre de 1972, pp. 20-22.

${ }^{21}$ Editorial, "1971 Año del VI Congreso Latinoamericano de Trabajadores", CLASC. Vocero del sindicalismo revolucionario en América Latina, Caracas, enero-febrero de 1971, p. 2. 
en Chile ${ }^{22}$ era que dicha situación de dominación/dependencia económica se estaba profundizando en la región, dado que la industrialización era "inducida, controlada y apropiada" por conglomerados económicos transnacionales, principalmente estadunidenses. Alertaba que a causa de ello los acuerdos de integración y comercio en favor de los países menos desarrollados en realidad estaban beneficiando a las subsidiarias latinoamericanas de dichas firmas. Proponía entonces a este organismo un cambio radical de estrategia, a favor del "desarrollo solidario de todos los pueblos" y la participación de las organizaciones obreras en la elaboración de nuevos planes y programas.

Resulta evidente que la CLASC/CLAT no esquivó una discusión tan propia de la época como fue el desarrollo en general y de la región en particular. Pero lo interesante es observar, comparativamente, cómo se ubicó en la dinámica del debate. Si atendemos a la demanda por "participación en el desarrollo" pareciera que la CLASC/CLAT no se diferenció de los planteamientos de otras organizaciones sindicales contemporáneas, por ejemplo, de su principal rival, la ORIT. Sin embargo, la perspectiva con que cada una se introdujo en la polémica es opuesta. Mientras que esta última reclamaba ser parte de los planes de desarrollo programados para la región apelando al lugar que para ello les destinaba la Alianza para el Progreso y el sistema de organismos panamericanos intergubernamentales, por tanto avalando sus programas de desarrollo e integración (Scodeller, 2017); el tono de la CLAT no sólo era de denuncia a dichas instituciones por cuanto en América Latina los trabajadores estaban marginados de la "gestión y control del desarrollo económico y social", ${ }^{23}$ sino que además cuestionaban el modelo de desarrollo capitalista y dependiente que buscaban implantar. La síntesis de ambas cuestiones, es decir, la aspiración de participación de los trabajadores, pero en el marco de un desarrollo humanista e integral, como veremos, estará dado por la propuesta de autogestión como forma de organización económica, política y social (Central Latinoamericana de Trabajadores, 1978, pp. 181-187).

${ }^{22}$ El título del informe presentado fue Las nuevas modalidades de la dependencia externa y de "modernización" de las economías latinoamericanas. "El peligroso desarrollismo", CLAT. Vocero del Movimiento de los Trabajadores comprometido con la liberación de los pueblos de América Latina, Caracas, abril de 1972, p. 12.

${ }_{23}$ "Primera conferencia internacional de sociología sobre la autogestión y la participación”, CLAT. Vocero del Movimiento de los Trabajadores comprometidos con la liberación de los pueblos de América Latina, Caracas, enero de 1973, p. 12. 
Este esbozo sobre las concepciones de la CLASC/CLAT, en relación con el desarrollo, permite advertir un corrimiento en su identidad socialcristiana. Sin romper con esa matriz, la irá radicalizando al son de la dinámica de confrontaciones sociales que ocurrían en la región,,$^{24}$ en un proceso de secularización que además compartía con sus organizaciones hermanas de la Смт. Si bien la crítica al capitalismo continuaba formulándose en clave humanista cristiana, se hará en un tono cada vez más radical.

En este proceso, cada vez con mayor claridad el tema del desarrollo se fue imbricando con la necesidad de "construir una nueva economía". ${ }^{25}$ Entendida como elaboración que debía provenir de las propias bases de la organización esta estuvo, a su vez, estrechamente articulada a la autogestión como modelo en que la economía quedaba "en manos de los trabajadores". De nuevo, sin desprenderse de su visión humanista, ello implicaba pensar en "una economía del hombre, de todo el hombre, de todos los hombres y de todo el pueblo" ${ }^{26}$ Nótese ya el agregado colectivo a la formulación original de la Teología del Desarrollo. A desandar el recorrido de cómo esta concepción se fue articulando, nos dedicaremos a continuación.

\section{LA AUTOGESTIÓN COMO HORIZONTE DEL DESARROLLO}

La CLASC/CLAT anudó su preocupación por la participación de los trabajadores en las esferas económica y política de la organización social a la experiencia yugoslava de autogestión. Dar cuenta de esta significaría un estudio

${ }^{24}$ Recordemos que la década de los setenta iniciaba con una serie de sucesos que daban cuenta del ascenso de la conflictividad social y de un reverdecer del clima de época revolucionario que caracterizó a esta etapa: el Cordobazo argentino de 1969, el triunfo de la Unidad Popular chilena en 1970, el surgimiento de guerrillas urbanas en el Cono Sur y la radicalización de las movilizaciones político-sociales de sectores estudiantiles, religiosos, culturales, académicos, etc. Fue también con el cambio de década que no sólo se incrementó la conflictividad laboral, sino que en muchos de los países latinoamericanos se produjo una radicalización política y un "giro hacia la izquierda" de la clase trabajadora (Roxborough, 1997).

25 "Congreso latinoamericano de bancarios acuerda nacionalización de la banca de América Latina con gestión decisiva de los trabajadores", CLASC. Vocero del sindicalismo revolucionario en América Latina, Caracas, septiembre de 1971, p. 1.

26 "Visita la ClAsc el Director de Relaciones Internacionales del Consejo Central de Sindicatos Yugoslavos", CLASC. Vocero del sindicalismo revolucionario en América Latina, Caracas, enero-febrero de 1971, p. 8 (cursivas mías). 
en sí mismo y de otra índole al que aquí nos interesa; por la complejidad y densidad del caso como por su extensión temporal y variantes, pero además, por la diversidad de interpretaciones y debates existentes alrededor de la experiencia. ${ }^{27}$ Metodológicamente además, no es nuestra intención definir al modelo yugoslavo como punto de partida inicial y estático en relación con el cual despejar otros, sino reponer el modo en que la CLASC/CLAT fue construyendo su aproximación al mismo: por qué le despertó interés, los mecanismos por los cuáles llegó a él, sus interpretaciones y reformulaciones, mediadas por otras organizaciones, lecturas y procesos históricos, como veremos a lo largo de este apartado.

A partir de 1969 se puede advertir un interés sistemático por parte de la CLASC en la experiencia de autogestión yugoslava. Según la prensa de la organización, el vínculo se habría iniciado a partir de una visita que realizó una delegación de sindicalistas yugoslavos, a fines de 1968, a su sede en Caracas, interesados en profundizar su conocimiento y contactos con una central obrera que reconocían por su antimperialismo y búsqueda de autonomía sindical. Los visitantes, a su vez, se ocuparon en divulgar su experiencia de autogestión. ${ }^{28}$

Es así como aproximadamente seis meses después, invitados por el Consejo Central de los Sindicatos Yugoslavos (CCSY), una delegación de la CLASC viajó a Yugoslavia. En una estadía de doce días, visitaron sindicatos, fábricas, centros asistenciales y unidades agrícolas de producción en Serbia, Macedonia y Eslovenia. ${ }^{29}$ Nuevamente, la CLAsc recibió la visita del director del Departamento de Relaciones Internacionales del CCSY, quien en esta oportunidad dictó dos conferencias sobre la autogestión de los trabajadores. $\mathrm{Y}$ a su vez, los latinoamericanos fueron invitados a realizar un nuevo viaje de estudios recorriendo diferentes empresas y regiones. ${ }^{30}$ Asistirían luego al II Congreso Nacional de Autogestores de Yugoslavia, realizado en Sarajevo a

${ }^{27}$ La bibliografía sobre el caso yugoslavo es abundante y variada, para una síntesis actualizada remitimos al artículo de Goran Musić (2011).

28 "Sindicalistas yugoslavos visitan sede central de la CLASC", CLASC. Vocero del sindicalismo revolucionario en América Latina, Caracas, enero-febrero de 1969, p. 10.

29 "Delegación CLASC visita Yugoslavia. Contactos con los trabajadores y con la experiencia de autogestión", CLASC. Vocero del sindicalismo revolucionario en América Latina, Caracas, septiembre-octubre de 1969, p. 8.

30 "Delegación CLASC visita Yugoslavia. Contactos con los trabajadores y con la experiencia de autogestión", CLASC. Vocero del sindicalismo revolucionario en América Latina, Caracas, septiembre-octubre de 1969 , p. 8 . 
fines de noviembre de 1970. ${ }^{31}$ También enviaron un representante a la Primera Conferencia Internacional de Sociología sobre la Autogestión y la Participación, realizada en diciembre de 1972 en Dubrovnik, donde sindicalistas, especialistas en la materia y técnicos de organismos internacionales debatieron en torno a distintas experiencias a nivel mundial..$^{32}$

Pero la participación de los trabajadores en el diseño y gestión de emprendimientos, tanto en la esfera económica como política, no era una novedad histórica que surja con la experiencia yugoslava. ¿Qué fue entonces lo que motivó el interés de la CLAsc por su modelo de autogestión? Como para tantos otros movimientos y organizaciones de lo que genéricamente se denominó Nueva Izquierda ${ }^{33}$ para la CLASC Yugoslavia representaba un país autónomo del bloque soviético, que había realizado un camino original de socialización y que además podía dialogar con sus concepciones sobre la propiedad como bien común. De allí que comenzaran esos asiduos intercambios a fin de empaparse de su modelo de desarrollo en términos teóricos y prácticos. La experiencia yugoslava resolvía, en principio, muchos de los dilemas no resueltos de una tercera vía que el sindicalismo de orientación socialcristiana aspiraba proponer. Engarzaba de forma muy fluida con una concepción cada vez más contundente entre la dirigencia de la CLASC/CLAT, por la cual la imaginación de una nueva sociedad y economía a construir debía ser fruto de la creatividad de los propios trabajadores; quienes no sólo debían ser los creadores sino los principales ejecutores de aquella. En este sentido, desde su perspectiva el proceso yugoslavo también resolvía el problema de un Estado que aplastaba la autonomía de los sujetos.

Pero tampoco se trataba de reproducir un esquema que más o menos se adaptase a sus concepciones político-ideológicas. En la inauguración del Congreso Latinoamericano de Trabajadores Bancarios, el secretario general Emilio Máspero sintetizó lo que venimos expresando. Definió a la CLAsc como

31 "Por una economía en manos de los trabajadores", CLASC. Vocero del sindicalismo revolucionario en América Latina, Caracas, mayo-junio de 1970, p. 11; "La CLASC asiste al segundo congreso de autogestores de Yugoslavia”, CLASC. Vocero del sindicalismo revolucionario en América Latina, Caracas, agosto de 1971, p. 3.

32 "Primera conferencia internacional de sociología sobre la autogestión y la participación”, CLAT. Vocero del Movimiento de los Trabajadores comprometidos con la liberación de los pueblos de América Latina, Caracas, enero de 1973, p. 12.

${ }_{33}$ El denominador que la CLASC/CLAT compartió con este conjunto heterogéneo de actores fue una clara definición anticapitalista que no los aproximaba mecánicamente al socialismo realmente existente, sino por el contrario a la búsqueda de nuevos lenguajes, prácticas políticas y modos de organización social y comunitaria. 
"profunda e irreversiblemente anticapitalista", a la vez que afirmó: "no podemos quedarnos en el anti porque nuestra misión histórica es construir una nueva sociedad, y por lo tanto una nueva economía", para luego argumentar:

Ya estamos fatigados y furiosos al mismo tiempo al constatar el fracaso de tantas teorías económicas copiadas en el extranjero y que obedecen a modelos de desarrollo económico que terminan haciendo más dependientes, más explotados y más enajenados a nuestros pueblos. ¡No copiemos más! Es necesario crear un nuevo pensamiento económico y esto debe ser hecho por los propios trabajadores. $^{34}$

La originalidad era también una de las virtudes que se reconocía al proceso encarado por los trabajadores yugoslavos. De hecho, ya en los inicios de este vínculo, cuando los delegados de este país presentaron su experiencia de autogestión, en la prensa de la CLASC se resaltaba que "no tienen modelo de donde copiarse" pues "no están por un tipo de socialismo burocrático". 35

El inicio de esta búsqueda por parte de la CLAsC coincide temporalmente con su nueva Declaración de Principios de 1968. En la misma, al referirse a la empresa sostenían: "El movimiento obrero debe orientar sus esfuerzos de pensamiento y acción en la realización de fórmulas de autogestión de la empresa y de la economía en general." ${ }^{36}$ A partir de entonces la insistencia sobre la importancia de la autogestión se volvería constante, y se desarrolló cada vez con mayor profundidad. Cabe señalar que en la concepción que la CLAT fue entramando a lo largo del tiempo, esta no se limitó a aspectos económicos (sea a nivel de empresa o de la economía en general), sino que suponía, llevaba directamente, a la práctica de "una auténtica, real e íntegra democracia”, pues además del poder económico colocaba el poder político en manos de los trabajadores. ${ }^{37}$ Este, enfatizaban, es el modo a través del cual se abrían

34 "Congreso latinoamericano de bancarios acuerda nacionalización de la banca de América Latina con gestión decisiva de los trabajadores”, CLASC. Vocero del sindicalismo revolucionario en América Latina, Caracas, septiembre de 1971, p. 1 (cursivas mías).

35 "Sindicalistas yugoslavos visitan sede central de la CLASC", CLASC. Vocero del sindicalismo revolucionario en América Latina, Caracas, enero-febrero de 1969, p. 10.

36 "Por una economía en manos de los trabajadores", CLASC. Vocero del sindicalismo revolucionario en América Latina, Caracas, mayo-junio de 1970, p. 11.

37 "Para realizar la autogestión hay que liquidar el actual sistema capitalista", CLAT. Vocero del movimiento de los trabajadores comprometidos con la liberación de los pueblos de América Latina, Caracas, julio-agosto de 1973, p. 17. 
"posibilidades de responsabilidad y participación" a los trabajadores, al asumir un papel determinante en la organización de la sociedad toda.

A la vez, sin mencionar ejemplos concretos, advertían sobre la distorsión del sentido de autogestión que suponían algunas experiencias latinoamericanas (denominadas como empresas comunitarias o cooperativas), por cuanto la autogestión no era realizable bajo el actual sistema capitalista. La misma exigía un proceso previo de liberación, de revolución política, económica, social y cultural. En otras palabras, era el "fundamento del nuevo proyecto histórico de nueva sociedad". ${ }^{38}$ Aplicarla de modo aislado en el marco de los esquemas vigentes cambiaba por completo su sentido. Al respecto alertaba como "en los propios EE. UU. y en otros países comienzan a interesarse en la autogestión como una forma nueva de 'relaciones humanas', de 'relaciones industriales' para aumentar la productividad, la falsa 'participación' del trabajador en la empresa y en la economía y evitar así indefinidamente el cambio radical del sistema capitalista. Más bien para reforzarlo." ${ }^{39}$

Buscó claramente alejarse de esa perspectiva. Desde su órgano de expresión periódico, en varias oportunidades se explicó el funcionamiento de la autogestión en Yugoslavia y sus ventajas. Se resaltaba la síntesis que suponía dicho modelo entre la propiedad social de los medios de producción y la gestión en manos de los trabajadores (quienes definían desde los planes de producción hasta sus ingresos y normas de disciplina). ${ }^{40}$ Se fue entonces explicitando y explicando, en teoría, qué se entendía por autogestión. Así, a través de sus publicaciones es posible precisar qué era lo que la CLAT recuperaba del modelo yugoslavo y, sobre todo, con qué sentidos. Entender esta especificidad es relevante ya que, como aludimos, el yugoslavo se había transformado en un ejemplo extendido también para los países del bloque capitalista que la propia CLAT denostaba, en gran medida en la versión edulcorada puesta en circulación por la oIT.

38 "Para realizar la autogestión hay que liquidar el actual sistema capitalista", CLAT. Vocero del movimiento de los trabajadores comprometidos con la liberación de los pueblos de América Latina, Caracas, julio-agosto de 1973, p. 17.

39 "Para realizar la autogestión hay que liquidar el actual sistema capitalista", CLAT, Vocero del movimiento de los trabajadores comprometidos con la liberación de los pueblos de América Latina, Caracas, julio-agosto de 1973, p. 17.

40 "Delegación CLASC visita Yugoslavia. Contactos con los trabajadores y con la experiencia de autogestión”, CLASC. Vocero del sindicalismo revolucionario en América Latina, Caracas, septiembre-octubre de 1969, p. 8. 
Así, en la marea de usos del concepto de autogestión que circulaban a nivel internacional, la Clat fue muy clara en sus delimitaciones. Pero llegar a estas no fue un proceso de diálogo unidireccional ni con un único interlocutor. En buena medida, la significación de la autogestión yugoslava fue mediada por la reapropiación que de la misma había realizado un referente cercano a la CLASC/CLAT dentro de la CMT, la Confederación Francesa Democrática del Trabajo (СFDT).

Es en parte a partir de la centralidad que la bandera de la autogestión ocupó en el Mayo Francés que la cLAsc tomó nota y comenzaría a interesarse por esta cuestión que sus pares de la CFDT ya venían discutiendo desde algunos años atrás. Efectivamente, al calor de aquel acontecimiento y abrevando fuertemente en la experiencia yugoslava en marcha (Georgi, 1995), la CFDT produce importantes aportes y reflexiones teóricas que influenciaron el campo del sindicalismo latinoamericano, sobre todo en Brasil (Iturraspe, 1986, pp. 36 y 51). Según el argentino Carlos Custer, entonces secretario general adjunto de la CMT, la CLAT tomó como insumos las producciones francesas en la materia ${ }^{41}$ lo cual puede observarse en los textos que, elaborados por dicha central sindical, eran traducidos y utilizados en distintas instancias de formación ya desde 1969. ${ }^{42}$

En camino a su VI Congreso de $1971,{ }^{43}$ la CLAT ya se definía claramente a favor de la propiedad social de los medios de producción y de la planificación democrática, ambos conceptos que, de la mano de la autogestión, eran bandera de la organización francesa. Como han señalado F. Georgi y L. Heerma van Voss (2005), es importante resaltar que las últimas dos nociones denotan la pervivencia de ciertos principios inherentes a la doctrina socialcristiana, a la vez que rupturas significativas. Por ello, si bien la смт adoptó formalmente estos tres pilares en los setenta, no todas las organizaciones miembro europeas lo hicieron con el mismo énfasis que la CFDT, o que la propia CLAT.

${ }^{41}$ Entrevista a Carlos Custer por Gabriela Scodeller, 1 de noviembre de 2018, Ciudad Autónoma de Buenos Aires, Argentina.

${ }^{42}$ Por ejemplo, ILATES. Apuntes para Organizadores Sindicales. IV Curso-Seminario Latinoamericano para Organizadores Sindicales de la CLASC, Caracas, 28 de junio al 27 de julio 1969. Colección August Vanistendael, BE/942855/757/1054. Aclaremos que hasta 1974 en que se inauguró la Universidad de los Trabajadores de América Latina (UTAL), el principal centro de formación de la CLASC/CLAT fue el Instituto Latinoamericano de Estudios Sociales "Humberto Valdés" (ILATES), cuyo funcionamiento comenzó a fines de 1966.

${ }^{43}$ La etapa abierta a partir de este congreso ha sido caracterizada por algunos estudiosos como la "fase ultraizquierdista" de la organización (Wahlers, 1991, cap. v). 
Por otra parte, el concepto de "planificación democrática" que la CFDT (entonces bajo su apelativo confesional, CFTC) incorporó a fines de los años cincuenta $^{44}$ difería del término de "planificación social" empleado en el sistema yugoslavo, y que a su vez se alejaba del modelo soviético de "planificación centralizada" (Zaccaria, 2018, p. 213). Ello nos está indicando no sólo la mediación de los sindicalistas franceses en la reflexión sobre el caso yugoslavo que operaba en la CLAT, sino la fuerza de esta. La incorporación de este concepto a la vez informaba y reforzaba el vínculo entre economía y política que nutría la noción "integral" de autogestión y democracia que, como vimos, sostenía la CLAT.

Si por un lado, desde esta última, el proceso yugoslavo fue mirado con una lente tonalizada por las resignificaciones de la CFDT, a la vez se reenfocaba a la luz de las dinámicas históricas que más próximamente tenían lugar en el continente. Así, en las definiciones más acabadas sobre autogestión que podemos encontrar hacia 1973-1974, se tornaron centrales sus propias perspectivas sobre la construcción de poder, influidas de modo particular por el devenir del proceso chileno. En términos generales, este se convirtió en una referencia concreta y cercana a partir de la cual discutir su concepción de sociedad y de individuo, de desarrollo económico y de democracia política, de revolución y el rol de las y los trabajadores en ella. Respecto de las cuestiones que se vinculan de modo más directo con este artículo, engrosó de modo directo sus reflexiones y postulados en torno a la autogestión, en particular en lo que hacía al rol del Estado.

En 1972, avanzado el gobierno de la Unidad Popular, la CLAT se manifestó en contra de las "fuerzas reaccionarias, de derecha, facistas [sic] que intentan bloquear el actual proceso político chileno", a la vez que realizó una serie de críticas al proceso en marcha. Festejaban que dos tercios de quienes votaron en 1970 se hubiesen manifestado "en contra del sistema capitalista y en favor de una sociedad socialista", pero defendían el derecho de "autodeterminación" del pueblo chileno para definir qué tipo de sociedad socialista se debía construir, no aceptando "cualquier tipo de socialismo". De lo contrario, sostenían dos referentes de la CLAT chilena, se operaría "un auténtico proceso de enajenación colectiva que es la negación misma de todo auténtico proce-

${ }_{44}$ Recordemos que la noción surgió en la Francia de posguerra donde la cuestión de la democracia resultaba central, específicamente del grupo minoritario de izquierda Reconstrucción (Georgi, 1995, pp. 33-39). 
so de liberación económica, social, política y cultural. En efecto, cambiar de patrón no es liberación." Esta última frase refería críticamente al paso hacia un capitalismo de Estado tal como lo propugnaba el Partido Comunista (PC), mientras que la CLAT reclamaba que el proceso de nacionalizaciones en los sectores estratégicos debía ir acompañado de fórmulas de gestión y control con mayor participación de los trabajadores. ${ }^{45}$

En julio de 1973, en su XIII reunión, el Consejo de la CLAT elaboró un documento -que formuló como un "llamado constructivo" al gobierno y distintas fuerzas populares y progresistas- en el cual los instaban a continuar el proceso de transformación dentro de las perspectivas de una "socialización liberadora" que debía desarrollarse sobre la base de la libre determinación de los trabajadores y el pueblo chileno. ${ }^{46}$ Así mismo, allí criticaban al gobierno de Salvador Allende por sus

claras muestras de intervenciones extranjerizantes, todo lo cual puede significar un mero cambio de patrón y una apropiación del poder y de los medios de producción en manos de tecno-burocracias estatales, desplazando a las clases trabajadoras de la gestión y control efectivos de todo el proceso, impidiendo que surjan fórmulas originales de autogestión de los trabajadores no solo en la economía sino en toda la sociedad chilena. ${ }^{47}$

Sobre todo en discusión con el PC -al que tildaban de stalinista-y su aparato sindical, proclamaban la construcción de un "socialismo democrático y autogestionario donde los trabajadores seamos la vanguardia". ${ }^{48}$ Así, los referentes de la CLAT se declaraban partidarios de la socialización de los medios de producción siempre que ello fuese acompañado por "fórmulas de control y de gestión que faciliten una verdadera autogestión de la economía por parte de los trabajadores, junto con una planificación democrática de la

45 "Chile: cambio de patrón no es liberación", CLAT. Vocero del movimiento de los trabajadores comprometidos con la liberación de los pueblos de América Latina, Caracas, julio de 1972, p. 6.

46 "La CLAT seguía con preocupación crítica y constructiva el proceso chileno", CLAT. Vocero del movimiento de los trabajadores comprometidos con la liberación de los pueblos de América Latina, Caracas, octubre-noviembre de 1973, p. 9.

${ }_{47}$ "La CLAT seguía con preocupación crítica y constructiva el proceso chileno", CLAT. Vocero del movimiento de los trabajadores comprometidos con la liberación de los pueblos de América Latina, Caracas, octubre-noviembre de 1973, p. 9.

48 "Chile: cambio de patrón no es liberación", CLAT. Vocero del movimiento de los trabajadores comprometidos con la liberación de los pueblos de América Latina, Caracas, julio de 1972, p. 6. 
misma". ${ }^{49}$ Reaparecen, ahora analizando una experiencia concreta latinoamericana, los tres conceptos clave de la propuesta de la CFDT.

En menor medida, otros casos históricos y contemporáneos fueron objeto de estudio por parte de los cuadros de la CLAT, en la medida que constituían insumos para el diseño de la nueva sociedad a construir y en la que la autogestión integral era el eje articulador.

\section{FORMACIÓN PARA LA NUEVA SOCIEDAD}

La propia CLAT, al declararse partidaria de la autogestión "como perspectiva original de control y gestión de la economía en manos del pueblo, de los trabajadores, de los usuarios, de los consumidores", enfatizaba que esta "no se copia ni se importa. Es una aspiración profunda del Movimiento de los Trabajadores, que se construye en la realidad original de cada país y de cada Continente" ${ }^{50}$ Con lo cual las referencias europeas, llegasen directamente desde Yugoslavia o mediatizadas por la reapropiación que de la misma hicieran los franceses, tenía que ser puesta en tensión con la realidad de un continente que ellos caracterizaban como dependiente. Efectivamente, otras experiencias de autogestión a escala regional (Chile, Perú, Argentina, entre otras) fueron discutidas en el seno de la CLASC/CLAT, aunque no fueran puestas en circulación a través de su órgano de divulgación periódico ${ }^{51}$-como hizo reiterativamente con el caso yugoslavo-, sino estudiadas en distintos eventos de formación.

Así, en el marco del Proceso Colectivo de Elaboración Ideológica (PCEI) que arrancó en 1973 con el objeto de llegar a elaborar desde las bases del movimiento el modelo de nueva sociedad que la CLAT aspiraba a construir, ${ }^{52}$ se

49 “Chile: cambio de patrón no es liberación”, CLAT. Vocero del movimiento de los trabajadores comprometidos con la liberación de los pueblos de América Latina, Caracas, julio de 1972, p. 6.

50 "Perspectivas y estrategia. El objetivo más importante del VI Congreso de la CLASC: construir el poder organizado de los trabajadores para la liberación y la nueva sociedad”, CLASC. Vocero del sindicalismo revolucionario en América Latina, Caracas, noviembre de 1971, p. 11 (cursivas del original).

51 Tanto la prensa (que a lo largo de los años tomó distintos nombres) como otros documentos editados desde Caracas tenían por destinatario a militantes y cuadros de distinto nivel.

${ }^{52}$ Diseñado y coordinado de modo centralizado, se buscaba la formación de los trabajadores de base a la vez que la recuperación de sus saberes e inquietudes. Funcionó a partir de Círculos de estudio que implementaban el Método de revisión de vida desarrollado por el fundador de la Juventud Obrera Católica (JOc), el belga J. Cardjin. Para dar cierta unidad al 
llevó a cabo en la UTAL el I Seminario Ideológico Latinoamericano, en el que vale la pena detenerse. Su título fue "La autogestión económica base de un proyecto alternativo de nueva sociedad". Fue pensado como una instancia de estudio y elaboración de materiales y propuestas que debían nutrir las instancias de formación política de las bases del Movimiento. ${ }^{53}$ Participaron de este encuentro dirigentes sindicales, pero también técnicos y expertos, convocados especialmente por su "práctica, estudio o investigación". Estos debieron realizar un proceso de "preparación remota y próxima" 54 sobre los distintos temas a abordar a lo largo de las dos semanas que duró el seminario desarrollado a fines de $1974 .{ }^{55}$

A lo largo de las jornadas se discutió, en primer lugar, un diagnóstico en términos económicos, políticos, sociales y culturales del capitalismo a escala global y en la región, con la mirada puesta en el impacto sobre los trabajadores y sus organizaciones. Luego se analizó desde el punto de vista teórico la socialización de los medios de producción, y a la luz de ello distintas experiencias históricas en América Latina y el mundo. Entre ellas, la de las comunidades industriales peruanas creadas durante el gobierno militar de Juan Velasco Alvarado; las más de 200 empresas autogestionadas que habían funcionado bajo el gobierno de la Unidad Popular en Chile; "la experiencia argentina con sus características propias"; ${ }^{56}$ los modelos de socialización de

proceso se escribieron una serie de cuadernillos temáticos por cada ciclo de estudio. Sobre esta experiencia y el proyecto pedagógico de la CLASC/CLAT consultar Scodeller (2016).

53 "I seminario ideológico latinoamericano: La autogestión económica base de un proyecto alternativo de nueva sociedad", CLAT. Vocero del movimiento de los trabajadores comprometidos con la liberación de los pueblos de América Latina, Caracas, noviembre-diciembre de 1974, p. 2.

${ }^{54}$ Este era un método de trabajo implementado en los seminarios de formación de cuadros, donde los asistentes debían prepararse previamente para el evento, a partir de una serie de materiales de lectura y tareas que le eran asignadas por la organización. En este caso, entre las actividades se les solicitó realizar un listado de los libros o documentos que circulasen en su país sobre la temática.

${ }^{55}$ UTAL. Circular 013/74. Asunto: Convocatoria al I Seminario Ideológico a Nivel Latinoamericano. San Antonio de los Altos, 23 de julio 1974. Colección August Vanistendael, BE/942855/757/340, KADOC.

${ }^{56}$ Aunque no se la nombra, por su contemporaneidad podemos suponer que se refiere a la experiencia de cogestión -aunque sus referentes hablaran de autogestión- de la empresa Servicios Eléctricos del Gran Buenos Aires (SEGBA), puesta en marcha una vez asumido el tercer gobierno peronista (1973-1976). Vale la pena traer el comentario del dirigente sindical y entonces presidente de SEGBA Juan José Taccone, quien recuerda una conversación, en 1973, junto al entonces secretario general de Luz y Fuerza, Oscar Smith, con Juan Domingo Perón al respecto: "Se habla ahí de comunidad organizada, se habla de comunidad de servicios y surge de 
la Unión Soviética y los países del bloque socialista; y en particular, el caso yugoslavo, caracterizado como el más "avanzado". ${ }^{57}$

Como se puede observar, todas las referencias remitían a casos surgidos -aunque con claros matices (sea mediante legislación, apoyo técnico o financiero)- al amparo del Estado. Llama la atención que no se analizasen aquellas experiencias que se gestaron contra el sistema jurídico o en el marco de confrontaciones político-sociales. ${ }^{58}$ Si bien las fuentes disponibles no nos permiten discernir el detalle de la evaluación que se hacía de cada uno y las discusiones detrás de los tópicos enunciados, en principio el recorte efectuado abre interrogantes en torno a la preocupación de la CLAT por el rol del Estado en los procesos de socialización. Parecería que, más allá de sus críticas a los procesos de burocratización, no habría posibilidad de pensarla al margen de un entramado institucional ya consolidado. Esto contrastaría, en principio, con su reiterada apelación no sólo a la autogestión sino a la autoorganización o al autogobierno, palabras con que evocaba su concepción del poder. De hecho, como resultado del seminario se pretendía llegar a esbozar una propuesta de autogestión micro y macroeconómica que se enmarcase dentro de la "Planificación democrática" ${ }^{59}$ Insistimos en la importancia que adquiere este concepto traído de la CFDT y que denota la búsqueda de democratización

Perón la idea de 'autogestión'. La denominación de 'autogestión' en nuestro caso nada tenía que ver con los yugoslavos. Les relato cómo fue. Se buscaba darle la forma a la palabra comunidad, entonces se llegó a la conclusión de que la mejor forma de definirla era mediante el término 'autogestión'. Preocupado por los etiquetamientos que pudieran ponernos le dije a Perón: 'Nos van a acusar de marxistas, General'. Perón sonrió y nos tranquilizó: 'La palabra autogestión no tiene nada de marxista, absolutamente. La palabra autogestión tiene valor cristiano y comunitario"” (Taccone, 1983, p. 18). La anécdota deja entrever, por un lado, lo equívoco del término, la multiplicidad de usos y sentidos en circulación -lo cual corrobora la importancia de conocer en cada caso cómo el mismo fue entendido y aplicado-. Por otro, muestra más allá de matices ideológicos, lo extendido del sustrato cristiano en muchas de las experiencias de participación obrera en los años setenta.

57 "I seminario ideológico latinoamericano: La autogestión económica base de un proyecto alternativo de nueva sociedad", CLAT. Vocero del movimiento de los trabajadores comprometidos con la liberación de los pueblos de América Latina, Caracas, noviembre-diciembre de 1974, p. 2.

${ }^{58}$ Por ejemplo, aquellas que F. Iturraspe agrupa como "contestatarias": las colectivizaciones españolas durante la guerra civil, los consejos obreros de la Italia de entreguerras, entre otras (Iturraspe, 1986, p. 21).

${ }^{59}$ UTAL. Circular 013/74. Asunto: Convocatoria al I Seminario Ideológico a nivel Latinoamericano. San Antonio de los Altos, 23 de julio 1974. Colección August Vanistendael, BE/942855/757/340, KADOC. 
"del poder, del tener y del saber" ${ }^{60}$ Es decir, la descentralización del poder tanto del capital como del Estado-, creando como nuevo centro el del pueblo organizado; tal como llegaría a definirse en el VII Congreso de 1978 (Central Latinoamericana de Trabajadores, 1978, pp. 181-187).

Puesto que sin el involucramiento de los trabajadores no habría una transformación real, la CLAT se preocupó por promover que dicha participación fuese consciente, a través de la formación de todos sus miembros. Con este objetivo, los cuadernillos elaborados para el trabajo de base dentro del PCEI divulgaron las ideas fuerza hasta aquí esbozadas, en términos sencillos y ofreciendo a su vez una mirada articulada de sus concepciones en materia de organización social. El Primer Ciclo, en el cual se proponía realizar un diagnóstico de la situación latinoamericana, concluía planteando que como parte del camino revolucionario que debían encarar los países pobres, debían transformarse "los modos de producción y cambiar cualitativamente la concepción de la propiedad, destinos de los ingresos y objetivo de la actividad económica"; mientras que en el plano social y político debía encararse la "creación de verdaderos canales de participación que posibiliten la autogestión social" (Central Latinoamericana de Trabajadores, s. f. a, tema Xv, p. 24).

Más concretamente, a lo largo del Segundo Ciclo de formación enfatizaban que la empresa, en tanto comunidad de trabajadores, debía ajustarse al Bien Común. Se exigía que el trabajador participe, de forma plena, en la toma de decisiones. El hombre no podía realizarse como persona humana en la empresa capitalista, explicaban, donde es explotado, donde se enajena su espíritu y queda reducido a un simple robot de producción o mera mercancía. Por ello el movimiento obrero debía orientar sus esfuerzos de pensamiento y de acción a la realización de fórmulas de autogestión de la empresa y de la economía en general. También la economía debía estar orientada, dirigida y controlada por los trabajadores organizados. Proclamaban, a fin de lograr una economía "humanista, comunitaria y democrática", "la democratización de la propiedad de los bienes de producción a través de la gestión comunitaria de todos los productores, cualquiera sea su aportación y especialidad, para lograr una efectiva socialización de los medios de producción".

${ }^{60}$ La nueva sociedad estaría signada por la "socialización de los medios de decisión, de producción y circulación, como de la cultura, la ciencia y la tecnología” (Central Latinoamericana de Trabajadores, 1978, pp. 181-187). 
En un plano más político, citando un documento de 1971, se afirmaba que el "socialismo comunitario" ${ }^{11}$ era la "síntesis histórica de la democracia autentica e integral: personalista, pluralista, comunitaria, inspirada en los valores originales del Movimiento de los Trabajadores y en los valores del humanismo cristiano". Si la socialización colocaba los bienes en general al servicio de todos los hombres, explicaban a sus bases que ello permitiría la realización, promoción y desarrollo integral de cada individuo, siempre en términos personales y colectivos. Les advertían, también, sobre la importancia de evitar el estatismo, la tecnocracia y la burocracia, que llevaban a la despersonalización. En la misma tónica divulgaban su objetivo de propiciar "una política de economía planificada, pero por métodos democráticos y populares, rechazando de plano todo predominio y monopolio burocrático y tecnocrático". El énfasis, una vez más, estaba puesto en transmitir la idea de construcción colectiva y creativa con base en esquemas y modelos propios, y a la "participación decisiva de los trabajadores organizados en la elaboración de los [planes de desarrollo], buscando llegar a la autogestión de la economía y al gobierno de la misma por los trabajadores y para beneficio de la nueva comunidad" ${ }^{62}$

Para finalizar, cabe señalar que a pesar de -o quizás por-los esfuerzos para definir en sus propios términos la autogestión y difundir esta concepción al interior de la propia organización, la cuestión quedó más bien confinada en un plano teórico. Dentro de este, las tensiones que se han ido despuntando a lo largo del texto se entrecruzaron con la laxitud con que se construyó su línea sindical, que osciló entre posiciones más o menos clasistas o reformistas (Scodeller, 2020; Wahlers, 1991). A la luz del devenir posterior-cruzado por el avance de políticas económicas neoliberales, regímenes autoritarios de derecha y el giro conservador dentro de la propia Iglesia católica- en que la propuesta sobre autogestión fue quedando rezagada, cabría preguntarse hasta qué punto logró, a lo largo de la década que aquí hemos reseñado, hacerse carne entre el conjunto de los trabajadores de la CLAT.

${ }^{61}$ Esta formulación fue parte del horizonte de un sector de la Democracia Cristiana en los setenta. Pudo escucharse de boca del candidato chileno en las elecciones de 1970, Radomiro Tomic. Posteriormente, se discutió extensamente en un Seminario de estudios sobre el Socialismo Comunitario realizado en Cartagena en 1973 (Partido Demócrata Cristiano Chileno, 1987, pp. 30-54).

${ }^{62}$ Si bien hemos evitado el entrecomillado, se respetó el sentido y vocabulario utilizado por la CLAT en los cuadernillos 3, 5 y 6 correspondientes al Ciclo II: Aportes de la CLAT al movimiento de los trabajadores, cuyos títulos respectivamente eran: Empresa-Propiedad-Economía; Política-Democracia; Desarrollo-Planificación-Integración (Central Latinoamericana de Trabajadores CLAT, s. f. b). 


\section{REFLEXIONES FINALES}

El recorrido realizado nos ayuda a aproximarnos a un actor escurridizo y difícil de definir por sus múltiples -y a veces en teoría contradictorias- adscripciones, y quizás por ello poco abordado en la historia del movimiento obrero latinoamericano.

Mirado desde el concierto mundial de debates, permite ubicarlo como parte del proceso de secularización que impregnó a las organizaciones sindicales de raigambre confesional en la época, y más específicamente en sintonía con las dinámicas de radicalización que dentro de dicho horizonte compartían las regionales de la Смт del tercer mundo y algunos sindicatos como el francés y el canadiense. En esta línea y en relación con la amplia circulación del modelo de organización económico yugoslavo, su diálogo directo con dicha experiencia a través de los viajes e intercambios o a través de la auscultación de la CFDT, le permitió recuperarla en su sentido más rupturista con el orden capitalista.

Ubicado en el contexto latinoamericano, nos muestra a un actor que no rehuyó a los debates sobre el desarrollo regional, aportando una solución que, en sintonía con la posición equidistante de la CMT respecto de los bloques comunista o capitalista, buscó alejarse de una confrontación que denunciaba como falaz. Aparece entonces la autogestión como un camino alternativo para emprender el desarrollo en América Latina. En esta construcción, la CLASC/CLAT recuperó y superó su matriz cristiana desde un posicionamiento revolucionario a la vez que tomó y resignificó la experiencia yugoslava en clave latinoamericana. Llegó así a esbozar su modelo de autogestión, como basamento de la nueva sociedad que imaginaba.

Los préstamos tomados de una Yugoslavia que, como para tantos otros, era referencia por cuanto proponía una vía socialista diferenciada del modelo soviético (la propiedad social, la descentralización de las funciones del Estado), a su vez en diálogo con un sindicalismo francés cristiano de izquierda (el socialismo democrático), operan sobre una base que, a pesar de su desconfesionalización, sigue siendo de raíz socialcristiana (el bien común, la empresa como comunidad, el desarrollo integral). Dichos préstamos se produjeron, además, en un universo de preocupaciones compartidas por las corrientes sindicales de distinto signo ideológico, las que discutían sobre el desarrollo, la planificación, la participación de los trabajadores en distintas instancias de gestión. Pero se leen desde una realidad específica (una región caracteriza- 
da como dependiente, subdesarrollada, acosada por los imperialismos) y a la luz de algunas experiencias regionales como las peruana, chilena y argentina (con matices todas surgidas al amparo de políticas estatales).

En estos cruces, y siguiendo su propia demanda de originalidad, la CLASC/CLAT se esforzó por dotar de una tonalidad específica al concepto de autogestión. La carnadura que le otorga no llegó, quizás por falencias propias, quizás por su misma prédica e insistencia en la esperanza creativa de las masas, a esbozarse más que como un modelo para armar, que debía proyectarse siguiendo la praxis de las y los trabajadores latinoamericanos -pero que quedó en el plano teórico-. Pero sí avanzó en definir sus contornos, y en este sentido la autogestión sería entendida como: integral, en tanto no se limitaba al ámbito de la empresa o de la economía, sino que involucraba todos los aspectos de la vida; anticapitalista, en tanto no había espacio para el desarrollo de este tipo de experiencias dentro de un sistema liberal; y vendría construida desde adentro y desde abajo, otorgando centralidad al movimiento de trabajadores organizados. La marca de agua estuvo dada nuevamente por su matriz cristiana, en tanto la autogestión se formuló en relación -como proceso y resultado- con el socialismo comunitario como modelo tentativo de nueva sociedad.

\section{LISTA DE REFERENCIAS}

Alexander, R. (2009). International labor organizations and organized labor in Latin America and the Caribbean. A history. California: ABC-CLIo.

Brands, H. (2010). Latin America's cold war. Cambridge: Harvard University Press.

Carew, A., Dreyfus, M., Van Goethem, G., Gumbrell-McCormick, R. y Van der Linden, M. (2000). The international confederation of free trade unions. Bern: Peter Lang.

Central Latinoamericana de Trabajadores (s. f. a). Proceso colectivo de elaboración ideológica. Ciclo I: Diagnóstico de la realidad nacional, latinoamericana y mundial. Caracas: FLACPO.

Central Latinoamericana de Trabajadores (s. f. b). Proceso colectivo de elaboración ideológica. Ciclo II: Aportes de la cLAT al movimiento de los trabajadores. Caracas: FLACPO.

Central Latinoamericana de Trabajadores (1978). La cLAT en la encrucijada. Informe político y de orientación presentado por Emilio Máspero, secretario general de la CLAT, a nombre del Comité Ejecutivo Latinoamericano, ante el VII Congreso de la CLAT. Caracas: FLACPO. 
Córdova, E. (1968). El neosindicalismo cristiano en la América Latina: CLASC. Revista de Ciencias Sociales, 12(2), 255-295.

Espagne, M. (1999). Les transferts culturels franco-allemands. París: Presses Universitaires de France.

Francis, M. (1968). Revolutionary labor in Latin America: the CLAsc. Journal of Inter-American Studies, 10(4), 597-616.

Georgi, F. (1995). L'Invention de la CFDT 1957-1970: syndicalisme, catholicisme et politique dans la France de l'expansion. París: Atelier.

Georgi, F. y Van Voss, L. H. (2005). Christian trade unionism and the organization of industry: from the organized profession to democratic planning and self-management. En L. H. van Voss, P. Pasture y J. de Maeyere (eds.), Between cross and class: comparative histories of christian labour in Europe 1840-2000 (pp. 225-249). Bern: Peter Lang.

Horn, G. (2015). The spirit of Vatican II. Western European progressive catholicism in the long sixties. Oxford: Oxford University Press.

Horn, G. (2008). Western European liberation theology: the first wave (1924-1959). Nueva York: Oxford University Press.

Horn, G. y Gerard, E. (2001). Left catholicism. catholics and society in Western Europe at the point of liberation 1943-1955. Lovaina: KADOC-Leuven University Press.

Iturraspe, F. (1986). La participación, la cogestión y la autogestión en el desarrollo de la democracia económica en América Latina. En F. Iturraspe (ed.), Participación, cogestión y autogestión en América Latina (t. 1, pp. 7-51). Caracas: Ed. Nueva Sociedad.

Löwy, M. (1999). Guerra de dioses: religión y política en América Latina. México: Siglo XXI.

Máspero, E. (1964). Latin America's labor movement of christian democratic orientation as an instrument of social change. En W. D’ Antonio y F. Pike (eds.), Religion, revolution, and reform. New forces for change in Latin America (pp. 161-181). Nueva York: Praeger.

Maul, D. (2017). Derechos humanos, desarrollo y descolonización. La Organización Internacional del Trabajo entre 1940 y 1970. Madrid-México: Plaza y Valdés Ed.

Musić, G. (2011). Yugoslavia: workers' self-management as state paradigm. En I. Ness y D. Azzellini (eds.), Ours to master and to own. Workers' control from the commune to the present (pp. 172-190). Chicago: Haymarket Books.

Partido Demócrata Cristiano Chileno (1987). El pensamiento de la Democracia Cristiana. Santiago de Chile: Taller E. Mounier. 
Pasture, P. (1994). Christian trade unionism in Europe since 1968. Tensions between identity and practice. Londres: Aldershot.

Rodríguez García, M. (2010). Liberal workers of the world, unite? The ICFTU and the defense of labour liberalism in Europe and Latin America (1949-1969). Bern: Peter Lang.

Roxborough, I. (1997). La clase trabajadora urbana y el movimiento obrero en América Latina desde 1930. En L. Bethell (ed.), Historia de América Latina (pp. 160-175). Barcelona: Crítica.

Saull, R. (2004). El lugar del sur global en la conceptualización de la guerra fría: desarrollo capitalista, revolución social y conflicto geopolítico. En D. Spencer (coord.), Espejos de la Guerra Fría: México, América Central y el Caribe (pp. 31-66). México: Porrúa.

Silva Gotay, S. (1981). El pensamiento cristiano revolucionario en América Latina y el Caribe. Implicaciones de la teología de la liberación para la sociología de la religión. Salamanca: Ed. Sígueme.

Scodeller, G. (2020). Una aproximación al universo ideológico de la Central Latinoamericana de Trabajadores a través de su proyecto de formación política (1954-1977). Izquierdas, 49, 493-515. DoI: http://dx.doi.org/10.4067/s0718-50492020000100228

Scodeller, G. (2017). Desarrollo, participación sindical y circuitos transnacionales de formación durante los años sesenta y setenta: el caso de las dirigencias latinoamericanas de la ORIT-CIOsL. Iberoamericana, XVII(64), 211-234. DoI: https://doi. org/10.18441/ibam.17.2017.64.211-234

Scodeller, G. (2016). Political training and social change in the 1960s and 1970s: the educational activities of the Latin American Central of Workers (CLAT). International Labor and Working-Class History, 90, 93-110. Dor: https://doi.org/10.1017/ S0147547916000193

Taccone, J. (1983). Autocrítica sindical, Buenos Aires: El Cid Editor.

Van der Linden, M. (2009). História do trabalho: ovelho, o novo e o global. Revista Mundos do Trabalho, 1(1), 11-26. DoI: https://doi.org/10.5007/1984-9222.2009v1n1p11

Van Voss, L. H., Pasture, P. y Maeyere, J. de (eds.). (2005). Between cross and class: comparative histories of Christian labour in Europe 1840-2000. Bern: Peter Lang.

Wahlers, G. (1991). Nace una alternativa. Miami: Saeta Ed.

Walters Jr., R. y Van Goethem, G. (2013). American labor's global ambassadors. The international history of the AFL-CIO during the cold war. Nueva York: Palgrave.

Werner, M. y Zimmermann, B. (2006). Beyond comparison: histoire croisée and the challenge of reflexivity. History and Theory, 45(1), 30-50. Dor: https://doi. org/10.1111/j.1468-2303.2006.00347.x 
Zaccaria, B. (2018). Learning from Yugoslavia? Western Europe and the myth of self-management (1968-1975). En M. Christian, S. Kott y O. Matějka (eds.), Planning in cold war Europe. Competition, cooperation, circulations (1950s-1970s) (pp. 213235). Berlín y Boston: De Gruyter.

\section{OTRAS FUENTES}

\section{Hemerografía}

CLASC (Confederación Latinoamericana de Sindicalistas Cristianos). Vocero del sindicalismo revolucionario en América Latina, Caracas, 1967-1971.

CLAT (Central Latinoamericana de Trabajadores). Vocero del movimiento de los trabajadores comprometidos con la liberación de los pueblos de América Latina, Caracas, 1971-1975. 